\title{
Política e Administração
}

\section{A. FONSECA PIMENTEL}

Subchefe do Gabinete Civil

da Presidência da República

Num estudo, como êste, em que se busca precipuamente analisar e definir - papel da política e da administração no processo do desenvolvimento, importa, antes de tudo, entendermo-nos sôbre o preciso significado que terão aqui os têrmos "política" e "administração", pois, como se verá adiante, a sua compreensão ou interpretação nem sempre se revela clara, pacífica e indisputável, inclusive nos próprios círculos especializados na matéria.

f́ a essa tarefa, por assim dizer, definitória, que nos dedicaremos nos parágrafos abaixo, adotando o seguinte esquema de estudo:

1. Dificuldades do problema.

2. O que nos ensina a etimologia.

3. O que é política e o que é administração.

\section{DIFICULdADES DO PROBLEMA}

Iniciando êste tópico, a primeira observação que gostaríamos de fazer é que, numa linguagem ideal, como um grande lingüista o externou, cada coisa, idéia ou conceito deveria ser expresso por um só vocábulo e, inversamente, cada vocábulo deveria exprimir somente uma coisa, idéia ou conceito (1).

Na prática, porém, assim não é (pelo menos desde o episódio da Tôrre de Babel). E muitas coisas, idéias ou conceitos, em qualquer idioma, são expressos freqüentemente por mais de um vocábulo; por outro lado, um grande número, senão a maioria, dos vocábulos possuem mais de um sentido.

Quanto mais ampla oū geral pareça ser a coisa, idéia ou conceito, tanto mais isso é verdadeiro.

No campo das ciências sociais, inclusive em seus ramos politico e administrativo, que são os que nos interessam aqui, a observação é particularmente exata no que concerne a generalidades do tipo das que são expressas por têrmos tais como "Estado", "govêrno", "sociedade", "poder", "política" e "administração".

Jacques Maritain exprimiu isso muito bem com as seguintes palavras:

"Não há tarefa mais ingrata do que procurar racionalmente distinguir ou definir, numa palavra, elevar a um nível científico ou filosófico, noções ou conceitos gerais que se originam das necessidades contingentes e práticas da história da humanidade e estão imbuídos de conotações sociais, culturais e históricas, apesar de conterem um núcleo de significação inteligível.

"Tais noções ou conceitos são fluidos e não fixos, mutáveis e inconstantes. Às vêzes, são empregados como sinônimos, às vêzes como antônimos. Todos se sentem mais à vontade usando êsses conceitos na medida em que o seu sentido preciso é obscuro. Mas, quando se procura defini-los e distingui-los, surgem numerosos problemas e dificuldades. Podemos meter-nos pela vereda errada na 
tentativa de revelar a verdade e de analisar e pôr em ordem as lições de uma experiência confusa da vida concreta.

"Essas observações aplicam-se, de maneira particularmente adequada, aos conceitos de Nação, Sociedade Política (ou Corpo Político) e Estado. Entretanto, nada é mais necessário para uma sadia filosofia política do que tratar de caracterizar essas três nocões e claramente identificar o autêntico sentido de cada uma." (2).

Hans Kelsen esbarra com as mesmas dificuldades ao procurar definir a Teoria Geral do Estado e o próprio Estado e assim se externa:

"A palavra que designa o objeto da Teoria Geral do Estado serviu de exemplo a um engenhoso escritor para pôr em evidência o fato de que o nome substantivo de uma ciência é sempre uma palavra a que se extraiu prèviamente todo conteúdo próprio; um substantivo costuma ser tanto mais aproveitável quanto mais vazio fôr; e de uma cabaça se pode fazer uma garrafa, esvaziando-a de seu conteúdo natural (MAUTHNER). Não importa em incorrer em contradicão com êsse paradoxo, ao afirmar (do ponto de vista da própria especialidade) que, em vez de a escassez de significados facilitar a linguagem, sucede, antes, que a superabundância de sentidos dificulte e torne quase impossível o uso da palavra Estado. Se a situação da teoria científica do Estado está longe de ser satisfatória, deve-se, sem dúvida, entre outras razões, à multiplicidade de significados que nos oferece a palavra, se bem que freqüentemente se procure substituir a formação científica de conceitos por uma noção insegura, vacilante e vulgar, com o propósito de fugir à dificuldade." (3).

E Kelsen acrescenta:

"Mas, não é só em sua relação com o conceito de sociedade que o Estado se mostra de tão variados significados. Mesmo dentro da Teoria Geral do Estado, como disciplina especial limitada a um fenômeno parcial das ciências sociais, o sentido da palavra oscila de um extremo a outro. Ora se pretende expressar por "Estado" a totalidade do objeto - que se diz, impròpriamen- te, composto de elementos - em contraposição às suas partes e, ao mesmo tempo, se identifica a palavra com cada um dêsses elementos: designa-se como Estado o poder específico que possuem determinadas coletividades; ou se fala de Estado e se pensa num povo; ou ainda se confunde Estado com um determinado território.

"E assim, como de um lado, o Estado significa o conjunto de todos os seus órgãos, por outro se aplica a mesma expressão sòmente para designar um ou outro de tais órgãos (por exemplo, para designar o chamado Govêrno)" ( $\left.{ }^{4}\right)$.

Em poucas palavras, os vocábulos de que nos estamos ocupando aqui, juntamente com os vultos conspícuos de Jacques Maritain e Hans Kelsen, são, em seu uso vulgar, imprecisos e evasivos, tendendo a dar a impressão de vagamente significarem apenas uma coisa. Todavia, quando os consideramos em sua função exata ou científica, vemos que êles comportam uma grande variedade de interpretações, as quais devem ser identificadas e precisadas, se queremos fazer progressos em nosso estudo e comunicar a terceiros os nossos pensamentos.

E o que pretendemos fazer agora com os têrmos "política" e "administração", começando por perscrutar a sua etimologia, pois, como muito bem observa Jellinek:

"A história da terminologia de uma ciência está estreitamente ligada à história da própria ciência em si, porque existe sempre uma correlação entre a palavra e o sentido que ela encerra. Não raro, foi a palavra que traçou o caminho da ciência num povo ou numa época." (5).

\section{O QUE NOS ENSINA A ETIMOLOGIA}

O vocábulo "política" procede do grego politikê, que significava a ciência das matérias do Estado, e tà politiká, que indicava os próprios negócios públicos. Ambas as expressões, por sua vez, como é sabido, provinham de pólis, cidade. Originàriamente, portanto, a política era a arte de conduzir uma cidade ou de tratar dos assuntos de interêsse público de uma cidade, visto como o Estado, na Grécia antiga, era usualmente a cidade Estado ou o Estado-cidade (6). 
O que fica acima explica por que a idéia fundamental, subjacente na palavra "política", é conduzir, dirigir, levar.

Bàsicamente, ocorreu coisa semelhante com o têrmo "govêrno", que veio do latim gubernatio, gubernare. Essas palavras, assim como o substantivo gubernaculum, leme, provieram de uma grande família grega de vocábulos correspondentes, dos quais os mais importantes eram kubernaô, originàriamente pilotar, no sentido literal da expressão, e daí, dirigir, conduzir, governar; kubernêtes, pilôto, timoneiro; e kubérnesis, pilotagem, arte do timoneiro. Por outro lado, é altamente provável que tôdas essas palavras procedam do sâncrito kubara, que significava varal do carro ou carroça:

Isso explicaria por que o govêrno, em várias línguas modernas, é, algumas vêzes, comparado figurativamente a uma nave ou carro, que devem ser conduzidos, como, por exemplo, na conhecida expressão "a nau do Estado".

Do que fica acima se pode também fàcilmente concluir que as palavras "política" e "govêrno" são de origem, por assim dizer, nobres, implicando, ambas, a idéia básica de comando ou direção.

O têrmo "administração" (do latim administratio, pràticamente sem alteração ortográfica), por outro lado, tem origem muito humilde. Provém, com efeito, de administrare, composto de ad, a, para, e ministrare, ajudar, auxiliar. Originàriamente, pois, "administrar" era assistir ou atender alguém no desempenho de uma tarefa, usualmente de natureza manual ou doméstica. Pois o verbo ministrare estava, òbviamente, ligado aos substantivos minister (masc.) e ministra (fem.), que, a princípio, significavam servente, empregado doméstico, e também a ministerium, que designava as tarefas ou deveres de um servente ou empregado doméstico, como se pode ver nas obras, entre outros, de Cícero, Vírgílio, Ovídio, Sêneca, Tito-Lívio (7).

No que concerne às origens mais remotas dos vocábulos minister, ministra e ministerium, alguns etimologistas relacionaram-nos, no passado, com manus, mão, mas hoje a sua derivação de minus, menos, parece firmemente estabelecida. Em qualquer dos casos, porém, aquelas palavras - de acôrdo com a etimologia - sempre tiveram uma evidente conotação de inferioridade, señdo de data relativamente recente 0 sentido e a importância que elas apresentam em nossos dias.

Mas, emergindo do mundo sepulto da etimologia para os domínios da moderna semântica e, em particular, das ciências politica e administrativa, o que realmente significam política e administração?

\section{O QUE E POLITICA E O QUE E ADMUNISTRAÇÃO}

Se consultamos os dicionários, verificamos que os têrmos politica e administração possuem grande variedade de significados.

Política, por exemplo, pode ter, entre outras, as seguintes acepções:

a) a arte ou ciência do govêrno;

b) a prática ou as atividades politicas;

c) o processo de adoção de diretrizes (policy-making, segûndo a terminologia anglo-saxônica) dentro do govêrno, ou a formulação do direito público positivo;

d) os negócios politicos, a vida política;

e) os princípios, convicções, opiniões ou simpatias politicas de uma pessoa, partido ou outro corpo coletivo;

f) a direção de negócios privados, ou política administrativa ou gerencial.

Administração, por sua vez, entre outros sentidos, pode ser entendida como:

a) a arte ou ciência da gerência;

b) o ato ou processo de administrar;

c) a execução das tarefas diretoras de uma instituição, emprêsa ou outra organização;

d) a atividade do Estado no exercício de seus podêres, ou, mais estreitamente, a atividade dos podêres executivo e judiciário, ou mais estreitamente ainda, a atividade do poder executivo na condução do govêrno;

e) as pessoas às quais se confere, coletivamente, a tarefa da execução das leis;

f) o têrmo durante o qual uma autoridade ou corpo administrativo desempenha as suas atividades.

Bàsicamente, o sentido que as palavras "política" e "administração" encerram no título dêste ensaio é aquêle a que se referem as letras c acima, ou seja, 
respectivamente, o de adoção de diretrizes (policy-making) e o de execução de diretrizes (policy-execution).

Emprestando a Woodrow Wilson as suas conhecidas palavras, poderíamos, em verdade, dizer aqui:

"A administração pública é a pormenorizada e sistemática execução do direito público. Tôda aplicação particular de lei geral é um ato de administração. O lançamento e a cobrança de impostos, por exemplo, o enforcamento de um criminoso, o transporte e a entrega das malas postais, o equipamento e o recrutamento do exército e da marinha etc. são todos, evidentemente, atos de administração; mas as leis gerais que determinam que essas coisas sejam feitas estão òbviamente fora e acima da administração. Os planos gerais de ação governamental não são administrativos, mas a sua execução particularizada constitui a administração" (8).

Ainda nos Estados Unidos, o mesmo pensamento seria muito bem expresso, um pouco mais tarde, por Goodnow, que escreveu ser a política a formulação da vontade do Estado e a administração, a execuçấo dessa vontade $(9)$.

A mesma coisa afirmou Leonard D. White quando escreveu que a "administração pública consiste de tôdas aquelas operaçốes que têm por finalidade a execução ou o cumprimento de diretrizes governamentais (public policy)" (10).

Por nossa vez, procurando penetrar no âmago dessas definições ou conceitos clássicos ou encarando-os por outro prisma, poderíamos dizer que a política e a administracão são processos básicos que o Estado utiliza para atingir os seus fins. A primeira, porém, está relacionada principalmente com os próprios fins do Estado, enquanto a última tem a ver, sobretudo, com os meios usados para atingir tais fins (11).

Em outras palavras, bàsicamente a escolha dos objetivos a serem atingidos é o campo específico da política, ao passo que a prestação de serviços para atingir tais objetivos é a área própria da administração. E já que o Estado, como mencionamos atrás, tem sido freqüentemente comparado a uma nave ou embarcação, ilustremos concretamente através dessa comparação a diferença fundamental entre o processo político e o processo administrativo.
Para conduzir corretamente uma nave ou embarcação, devemos: em primeiro lugar, determinar o pôrto ou lugar a ser atingido; em segundo lugar, estabelecer o roteiro a ser seguido; e, em terceiro lugar, levar a efeito, concretamente, a viagem planejada.

O primeiro passo da série de ações indicada é, geralmente, adotado pelo dono da nave ou embarcação, seja êle um indivíduo ou uma organização. Já o segundo passo é da responsabilidade principal do comandante da nave ou embarcação, com a eventual assistência do respectivo corpo de oficiais. Finalmente, o terceiro passo é executado por tôda a tripulação da nave ou embarcação, sob a supervisão e responsabilidade suprema do comandante.

Se examinamos mais de perto os diversos passos indicados, verificaremos que êles não são da mesma natureza e, pelo contrário, apresentam características próprias e fàcilmente distinguíveis, a saber: o primeiro envolve decisão quanto ao fim ou objeto da viagem; 0 segundo envolve também decisão, mas sòmente em relação ao roteiro a ser seguido para a execução da viagem; e o terceiro envolve apenas execução e não decisão, ou, se alguma decisão existe, é sôbre pontos tão secundários ou menores que ela tem pouco ou nenhum efeito sôbre o processo global de que nos estamos ocupando aqui.

$\mathrm{Na}$ nave ou embarcação chamada Estado, as coisas se desenvolvem mais ou menos da mesma maneira. Assim, podemos sintetizar as nossas considerações, dizendo que:

1) a política, ou condução dos negócios públicos, envolve fundamentalmente decisões concernentes aos fins ou objetivos do govêrno, que é o Estado em ação;

2) a administração, ou prestação dos serviços públicos, envolve fundamentalmente a execução das atividades necessárias à colimação dos fins ou objetivos do govêrno (12).

Mas, o que dizer da zona intermediária de decisão concernente ao roteiro, isto é, aos meios, mencionada em nossa comparação de uma nave ou embarcação com o Estado?

Diriamos que essa zona - uma zona cinzenta entre a zona branca da politica e a zona preta da administração ou vice-versa - é predominantemente 
administrativa. Mas, se a escolha dos meios afetar substancialmente a consecução dos objetivos, a decisão concernente aos meios pode tornar-se uma questão política e, às vêzes, uma questão política da mais alta importância.

Para dar uma ilustração muito atual, diremos que a declaração de guerra é um ato tipicamente político e que a condução da guerra em si é de natureza administrativa, Interessando bàsicamente à administração militar dos países envolvidos no conflito. Mas a decisão de usar armas nucleares, pelo menos nas atuais condições do mundo, é uma decisão de grande transcendência política (não obstante ser um dos meios da guerra) pelas implicações que poderia ter em tôda a situação política internacional.
Resumindo as nossas considerações, poderemos dizer, de maneira sucinta, que, dentro do Estado ou govêrno, assim como de uma organização privada, as decisões concernentes a fins são pura política ou adoção de diretrizes (policymaking); a execução ou prestação de serviços para atingir fins é pura administração ou cumprimento de diretrizes (policy-execution); as decisões concernentes a meios são, usualmente, o campo da administração, mas, se afetam substancialmente, a colimação dos fins, podem converter-se em matéria política.

Por outro lado, se quisermos visualizar de maneira concreta os conceitos expostos e representar gràficamente 0 que é política e o que é administração, poderíamos, a grosso mođo, compor o seguinte diagrama:

\begin{abstract}
Decisão quanto a fins
$1 \longrightarrow 1$

Política
\end{abstract}

Decisão quanto a meios

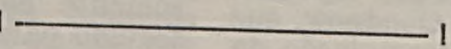

Usualmente administração, mas, em alguns casos, pode ser política ${ }^{(13)}$
Execução

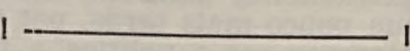

Administração

\section{I}


Para concluir as nossas considerações, diríamos que a distribuição da política e da administração entre os três Podêres ou funções clássicas do Estado seria, a grosso modo e esquematizando muito as coisas para fazê-las representáveis gràficamente, mais ou menos a seguinte:

PODER

PODER

LEGISLATIVO

EXECUTIVO

PODER

JUDICIÁRIO

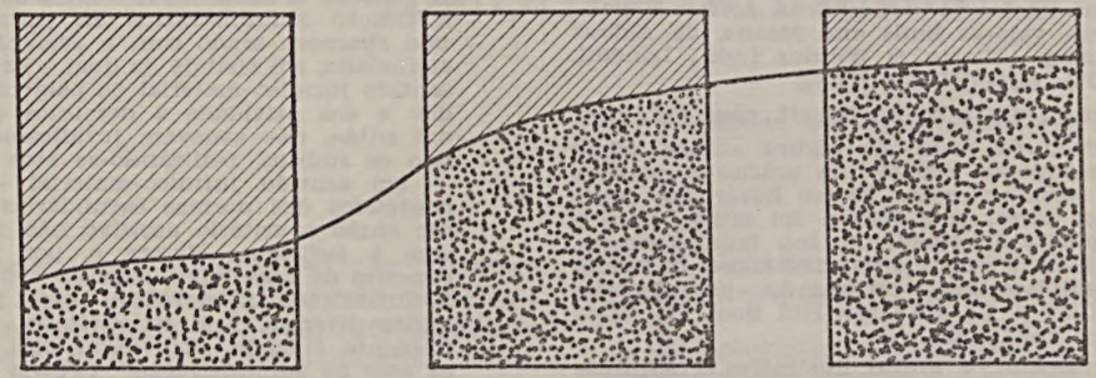

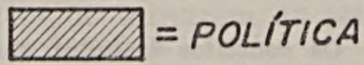

E claro que, de acôrdo com essa concepção, a função judiciária seria considerada uma função também eminentemente administrativa - a administração

\section{Fi:}

da justiça - com poder de discrição mais limitado do que o da administração pròpriamente dita (16).
(1) Albert Dauzat, La philosophie du langage, p. 23, Ernest Flammarion, Paris, 1912.

(2) The Man \& the State, p. 1, Hollis \& Carter, London, 1954. (Tradução inglêsa).

(3) Teoria General del Estado, p. 3. Editôra Nacional, S.A., México, DF., 1951 (Traduçăo espanhola).

(4) Op. cit., p. 4. Os mesmos conceitos, por outras palavras, săo expressos pelo tratadista mexicano Francisco Porrua Pérez. (Teoría del Estado, p. 12, Editorial Porrua, S.A., México, DF, 1954).

(5) Georg Jellinek, Teoría General del Estado, p. 95, Editorial Albatrós, Buenos Aires, 1954.

(6) Os gregos, pelo menos até os inícios do chamado período macedônio de sua história, näo conheceram Estado com população superior a 70.000 habs., e superficie superior a $10.000 \mathrm{~km}^{2}$. Essas eram, em verdade, a populaçâo e a superfície aproximadas de Esparta, a maior de tôdas as cidades-Estado gregas, no auge do seu desenvolvimento. (Emil Nack e Wilhelm Waegner, Grécia, trad. espanhola, p. 126, Editorial Labor S. A., Barcelona, 1960). Mas, usualmente, como moderno erudito o indica, as cidades gregas apareceriam, aos nossos olhos, como verdadeiras vilas. (T.R. Glover, The Ancient World, p. 93, Penguin Books, London, 1944). Para Platấo (República, o número de cidadăos num Estado perfeito deveria variar entre 1.000 e 5.040 (Leis, 737, c-d), ao passo que Aristóteles (Política, IV, 4), sem fornecer uma cifra precisa, afirma que o número de cidadáos de uma cidade (excluídos os escravos e demais năo-cidadăos) devia ser tal que "cada um conhecesse os outros pessoalmente”. É preciso, porém, nắo esquecer que nas antigas cidades gregas o número de cidadăos era, náo raro, excedido, de muito, pelo número de escravos (doúloi), estrangeiros (bárbaroi) e metecos (métoikoi), espécie de estrangeiros residentes ou estrangeiros com alguns direitos. (Fustel de Coulanges, La cité antique, Hachette \& Cie, Paris, 1893).

(7) Lemos, por exemplo, em Sêneca: "Servos non ministeriis aestimabo, sed moribus, ou seja, "Năo estimarei os escravos por seus servicos, mas por seus costumes"; ou em Tito-Lívio: "Quod ministerium fuerat, ars haberi coepta, isto é, "O que era trabalho de um servo tornou-se uma arte".

(8) "The Study of Administration" in Political Science Quarterly, v. II, p. 212, Ginn and Company, New York, 1887.

(9) Frank J. Goodnow, Politics and Administration, p. 22, The MacMillan Co., New York, 1900 (Apud Dwight Waldo, Teoria Política de la Administración Pública, versăo espanhola da obra The Administrative State, p. 166, Editorial Tecnos S.A., Madrid, 1961).

(10) Introduction to the Study of Public Administration, p. 3, 3rd. ed., The MacMillan Company, New York, 1948.

(11) Chamamos a politica e a administraçáo de processos de açáo estatal, para distingui-las das funçốes do Estado (legislativa, executiva, judiciária) e das atividades do Estado (militares, econômicas, sociaís etc.). É óbvio que se trata de uma distinçăo arbitrária, que pode, inclusive, ser questionada, mas que é preferível ao emprêgo indiscriminado 
de tais expressões, sem nenhuma ordem ou sistemática, como é feito, não raro, por autores diversos, mesmo eminentes.

(12) Mutatis mutandis, êsses conceitos se aplicam igualmente à administração privada.

(13) Paul Appleby tratou extensivamente do problema relativo às decisóes concernentes a fins e a meios, no seu excelente Policy and Administration (University of Alabama Press, University, Ala., 1949). Para um amplo e exaustivo estudo da matéria, em suas implicações filosóficas, sociais e políticas, veja-se Ends and Means, de Aldous Huxley (Chatto \& Windus Ltda., London, 1937).

(14) Apud Dwight Waldo, Op. cit., págs. 172 e segs.

(15) Wilson foi dado por alguns autores como pretendendo separar na prática a política da administraçăo. Parece haver um equívoco nisso, pois wilson foi muito claro e explícito a respeito no seu famoso ensaio. Veja-se, ademais, Ideas and Issues in Public Administration, organizado por Dwight Waldo, p. 72, Mc Graw-Hill Book Co., Inc.,
New York, 1953.

(16) A respeito, é muito ilustrativa a seguinte passagem de Kelsen sôbre a separação da administração e do que êle chama a jurisdição: "As constituições modernas não só estão submetidas ao princípio de uma separação da legislação e da execução, mas também ao da separação das duas funçốes que compōem, por igual, a última: a administração e o poder judiciário, designado por jurisdição ou justiça. Năo é fácil justificar o último princípio como postulado de política do Direito, pois é falso (ou só em parte verdadeiro) o suposto evidente do postulado separatista, que pretende encomendar tais funçốes a órgấos distintos: a hipótese segundo a qual se trata de duas funçőes essencialmente diferentes, cuja união em um mesmo órgão seria prejudicial em virtude de sua diversidade. Como queira que, atendendo ao conteúdo da função, a administraçăo é jurisdição no mesmo sentido que a justiça, não se concebe que se possam separar essas funções, considerando a sua natureza. E, enquanto a administraçăo só foi jurisdiçã̃o nesse sentido (a saber, de estabelecimento ou preparação processual de um ato coativo), nấo se falou nem de diversidade nem de separação de ambas as funçōes. A necessidade teórica de separar a função administrativa da jurisdicional não apareceu senão com a evolução antes assinalada, em virtude da qual o Estado, no sentido jurídico-material da palavra, estendeu a sua atividade a domínios em que, até então, năo atuavam juridicamente senăo os súditos, realizando-se atos estatais - em sentido jurídico-material - como conteúdos das normas secundárias; a náo ser então o critério decisivo não foi visto com a suficiente clareza e, por isso, no conceito de uma administração contraposta à jurisdição se incluíram atos jurídicos muito diversos. A linha divisória, arbitràriamente traçada, atravessou pela metade os atos da administração." (Teoría General del Estado, p. 339, Editorial Nacional, México, 1959).

NOTA: Os conceitos emitidos neste artigo já foram, em grande parte, objeto de estudo em dois trabalhos do autor aparecidos sob a forma mimeografada, a saber: Teoría del Estado y Administración Pública, 2 vols., San José, Costa Rica, 1964 (súmulas de aulas dadas no Instituto Centroamericano de Administración Pública); e Politics and Administration, Roma, 1966 (estudo em inglês preparado pelo autor para distribuiçẫo na FAO). 